\title{
Faktor-Faktor Yang Mempengaruhi Tingkat Kolektibilitas Debitur di PT. Bank China Construction Bank Indonesia Tbk.
}

Anggun Himawan, Gunawan Syahputra Wijaya, Wahid Mahmud, Zainul Arifin

School of Business and Economics Universitas Prasetiya Mulya

JL. RA. Kartini (TB Simatupang), Cilandak Barat Jakarta Selatan, Jakarta 12430 Indonesia.

*. Corresponding Author: anggun.himawan@gmail.com

\begin{tabular}{|c|c|}
\hline Abstract & \\
\hline $\begin{array}{l}\text { This research investigates the relationship between factors } \\
\text { owned by a debtor with the ability of a borrowed refund } \\
\text { (collectability) in the PT. Bank China Construction Bank } \\
\text { Indonesia Tbk (CCBI). This is based on previous research that } \\
\text { there is an influence between demographic factors and other } \\
\text { factors such as the amount of credit card ownership against } \\
\text { level of collectability. The data used are secondary data from } \\
\text { CCBl and we find not all demographic factors have an effect on } \\
\text { collectability level, including the amount of credit card } \\
\text { ownership. But the factor of work experience / business } \\
\text { influences the level of collectability. }\end{array}$ & \multirow{3}{*}{$\begin{array}{l}\text { Keyword: collectability - } \\
\text { demographic - bank } \\
\text { Kata Kunci: kolektibilitas - } \\
\text { demografi - bank }\end{array}$} \\
\hline ABSTRAK & \\
\hline $\begin{array}{l}\text { Penelitian ini akan mencari hubungan antara faktor-faktor yang } \\
\text { dimiliki seorang debitur dengan kemampuan pengembalian } \\
\text { dana yang dipinjam (kolektibilitas) pada PT. Bank China } \\
\text { Construction Bank Indonesia Tbk (CCBI). Hal ini didasari pada } \\
\text { penelitian sebelumnya bahwa ada pengaruh antara faktor } \\
\text { demografi dan faktor lain misalnya jumlah kepemilikan kartu } \\
\text { kredit terhadap tingkat kolektibitas. Data yang digunakan } \\
\text { adalah data sekunder dari CCBI dan hasil penelitian } \\
\text { menunjukkan bahwa bagi debitur CCBI tidak semua faktor } \\
\text { demografi berpengaruh pada tingkat kolektibilitas, termasuk } \\
\text { jumlah kepemilikian kartu kredit tidak ikut menentukan tingkat } \\
\text { kolektibilitas debitur. Namun faktor pengalaman } \\
\text { bekerja/bisnis berpengaruh terhadap tingkat kolektibilitas }\end{array}$ & \\
\hline
\end{tabular}




\section{PENDAHULUAN}

Berdasarkan Undang-Undang No. 7 Tahun 1992 sebagaimana diubah dalam UU no 10 tahun 1998, bank adalah badan usaha yang menghimpun dana dari masyarakat dalam bentuk simpanan dan menyalurkannya kepada masyarakat dalam bentuk kredit dan atau bentukbentuk lainnya dalam rangka meningkatkan taraf hidup rakyat banyak. Sebutan bank umum diberikan bila bank melaksanakan kegiatan usaha secara konvensional dan atau berdasarkan prinsip syariah yang dalam kegiatannya memberikan jasa dalam lalu lintas pembayaran. Fungsi penghimpun dan penyalur dana yang dilakukan oleh bank umum akan diawasi oleh Otoritas Jasa Keuangan (OJK) sesuai dengan UU no. 4 tahun 2011 yang disebutkan dalam pasal 4 bahwa OJK dibentuk dengan tujuan agar keseluruhan kegiatan dalam sector jasa keuangan terselenggara secara teratur, adil dan transparan, akuntabel dan mampu mewujudkan system keuangan yang tumbuh secara berkelanjutan dan stabil, serta mampu melindungi kepentingan konsumen maupun masyarakat.. Pasal 6 UU no. 21 tahun 2011 menyebutkan bahwa OJK melakukan pengaturan dan pengawasan terhadap kegiatan usaha bank dan pengawasan mengenai kesehatan bank yang meliputi : likuiditas, rentabilitas, solvabilitas, kualitas asset,rasio kecukupan modal minimum, batas maksimum pemberian kredit, rasio pinjaman terhadap simpanan dan pencadangan bank, laporan bank,system informasi debitur, pengujian kredit dan standar akuntansi bank.

Bank umum dalam menjalankan fungsinya sebagai penghimpun dan penyalur dana masyarakat dalam bentuk kredit akan mendasarkan keputusan besaran kredit yang disalurkan sesuai aturan. Penyaluran kredit akan dipertimbangkan untuk debitur yang dianggap memiliki kapabilitas dalam mengelola kredit. Menjadi tugas bank agar kualitas kredit tidak masuk dalam poin selain lancar, namun pada kenyataannya kredit bermasalah tidak dapat dihindarkan.

Ada banyak faktor yang menyebabkan kredit bermasalah diantaranya kemampuan debitur dalam mengelola keuangan, unsur kesengajaan ataupun bencana alam. Paper ini akan membahas dari sisi bank dalam mengenali calon debitur, karena keputusan pemberian kredit diberikan oleh bank setelah melalui proses pengenalan debitur yang dilakukan dalam waktu singkat. Proses pengenalan hanya didasarkan pada beberapa data permulaan yang diminta dari debitur dan kemudian di analisa oleh pihak bank.

Data permulaan yang diminta oleh calon debitur diantaranya adalah jumlah kartu kredit yang dimiliki, jenis kelamin, tanggal lahir, pendidikan, pengalaman (lama bekerja/usaha), 
status perkawinan, jumlah tanggungan dan besaran pendapatan per bulan. Data-data ini kemudian diolah oleh bagian kredit dan dilakukan wawancara terhadap calon debitur kemudian dibuat keputusan untuk diberikan kredit atau tidak. Keputusan yang diambil dalam waktu kurang lebih satu bulan berdasarkan data-data permulaan calon debitur bisa menimbulkan bias dalam pengambilan keputusan karena masih mengutamakan unsur subyektifitas.

Masalah penelitian yang diangkat dalam paper ini adalah : apakah variabel-variabel yang tercantum dalam data-data permulaan calon debitur dapat menggambarkan prediksi tingkat kolektibilitas kredit. Kemudian variabel-variabel apa sajakah yang secara signifikan berpengaruh terhadap tingkat kolektibilitas kredit calon debitur.

Paper ini akan menggambarkan hubungan antara tingkat kolektibilitas dengan faktor demografi seorang debitur serta jumlah kepemilikian kredit pada PT. Bank China Construction Bank Indonesia, Tbk. Analisa regresi dilakukan pada data sekunder dari bank untuk mengetahui faktor-faktor dominan yang bisa menggambarkan tingkat kolektibilitas debitur.

Manfaat yang diharapkan dari hasil penelitian adalah meningkatkan keakuratan bank dalam melakukan analisa profil resiko calon debitur dan memprediksi tingkat kolektibilitas kredit serta penerapan metode yang sama di berbagai sektor pemberian pinjaman (i.e leasing) yang lebih luas.

\section{TINJAUAN PUSTAKA}

Kredit bila ditinjau dari Kamus Besar Bahasa Indonesia memiliki arti pinjaman uang dengan pembayaran pengembalian secara mengangsur. Menurut UU No. 10 tahun 1998 kredit adalah penyediaan uang atau tagihan yang dapat disamakan dengan itu, berdasarkan persetujuan atau kesepakatan pinjam meminjam antara bank dan pihak lain yang mewajibkan pihak peminjam untuk melunasi utangnya setelah jangka waktu dengan pemberian bunga. Sebagai salah satu produk dan tugas dari bank maka kredit bisa menjadi tolok ukur keberhasilan sebuah bank dalam pengelolaan keuangan atau justru menjadi masalah bagi bank itu sendiri. Tingkat kolektibilitas sangat menentukan dalam tata kelola kredit ini dan hal ini menjadi perhatian tersendiri bagi OJK untuk melakukan tugas pengawasannya berdasarkan undang-undang. Pengelolaan kredit bank menjadi perhatian karena kredit bank tidak hanya berpengaruh pada kestabilan bank itu sendiri tapi juga kepada stabilitas ekonomi (Salina Kassim, M.Shabri 2008) selain itu stabilitas perbankan berpengaruh pada stabilitas moneter 
(Perry Warjiyo 2006). Peraturan Bank Indonesia No. 14/15/PBI/2012 membagi kriteria kualitas kredit yang disalurkan oleh perbankan seperti berikut ini :
a. Lancar
$0-1$ hari
b. Dalam perhatian khusus
$1-90$ hari
c. Kurang Lancar
91 - 120 hari
d. Diragukan
120 - 180 hari
e. Macet
$>180$ hari

Beberapa data permulaan yang diminta oleh pihak bank dari calon debitur di gunakan dalam penelitian ini, diantaranya adalah jumlah kepemilikan kartu kredit. Menurut Asosiasi Kartu Kredit Indonesia, jumlah kartu kredit yang beredar di Indonesia sampai dengan tahun 2016 adalah 17.406.327 kartu dengan nilai transaksi dalam juta adalah Rp. 272.950.051,-Kartu kredit menjadi fakta bagi perilaku konsumen saat ini, dan akan mempengaruhi pola belanja dan perilaku pelunasan di masa depan (Mansfield, Pinto, Robb 2013). Penelitian di Malaysia menunjukkan jumlah kepemilikan kartu kredit berpengaruh signifikan terhadap tingkat penggunaan (Ramayah dll 2002). Namun konsumerisme dengan banyak kartu kredit juga menyebabkan kebangkrutan bagi penggunanya di Malaysia (Noordin, Zaherawati, dll 2012). Study di Bostwana sebagai salah satu negara berkembang juga menunjukkan bahwa semakin banyak kartu kredit yang dimiliki semakin tinggi kecenderungan menunggak pembayaran (Clara 2012)

Data demografi yang menjadi bahan pertimbangan pihak bank dan akan dipakai dalam penelitian ini dalam menilai debitur diantaranya adalah jenis kelamin, usia, pendidikan, pendapatan, pengalaman, status perkawinan dan jumlah tanggungan. Jenis kelamin (wanita), usia dan pendidikan berpengaruh pada resiko gagal bayar namun tidak berpengaruh untuk jumlah tanggungan (Nijam 2013). Pengalaman seseorang dalam berbisnis mempengaruhi kemampuan dalam membayar pinjaman (Koesrindartoto \& Pratiwi 2010). Pendapatan, usia, gender, pendidikan berpengaruh terhadap pengembalian kredit (Waweru 2010). 
Penelitian ini fokus pada 5 variabel yaitu kepemilikian kartu kredit, jenis kelamin, tingkat pendidikan, pengalaman (usaha atau kerja), status perkawinan.

\section{METODOLOGI PENELITIAN DAN HIPOTESA}

Penelitian dilakukan dengan menggunakan data dari CCBI. Pengambilan data dilakukan dengan mengajukan permohonan kepada pihak bank untuk mendapatkan data permulaan yang diberikan oleh debitur kepada bank pada saat mengajukan kredit. Data yang diminta tergolong rahasia sehingga untuk nama debitur tidak disebutkan. Data yang didapat merupakan data debitur eksisting yang diambil dari periode 2010 -2016. Data didapat sebanyak 68 debitur yang diambil mewakili wilayah Jakarta, Bandung, Palembang, Pekanbaru, Batam, Lampung dan Surabaya.

Data yang diambil untuk analisa ini adalah sebagai berikut :

1. Kolektibilitas pinjaman

Penggolongan kolektibilitas kredit berdasarkan surat keputusan direksi Bank Indonesia No. 30/267/KEP/DIR, Tanggal 27 Februari 1998 tentang kualitas produktif dan pembentukan cadangan, ditetapkan 5 (lima) golongan kolektibilitas kredit yaitu : Lancar, Dalam Perhatian khusus, Kurang Lancar, Diragukan dan Macet.

a) Lancar

Yang dimaksud dengan status lancar pada status kolektibiltas adalah :

- Debitur menyelesaikan seluruh kewajibannya tepat waktu, artinya pembayaran angsuran (pokok pinjaman maupun bunga) tidak melewatii jadwal yang telah disepakati pada saat pengikatan (akad kredit).

- Terjadi keterlambatan pembayaran kewajiban bunga dana tau pembayaran angsuran (pokok dan bunga) namun tidak melewati bulan pembayaran kewajiban. Contoh : Seorang debitur memiliki jadwal pembayaran angsuran atas fasilitas KPR-nya setiap tanggal 25, dan debitur baru membayar pada tanggal 27. Memang terjadi keterlambatan 
namun tidak melewati bulan pembayaran sehingga status kolektibilitas yang dilaporkan ke Bank Indonesia adalah lancar.

b) Dalam perhatian khusus

Yang dimaksud dengan status dalam perhatian khusus adalah :

- Terdapat tunggakan kewajiban (angsuran pokok dan bunga maupun bunga saja) maksimal sampai dengan 90 hari.

c) Kurang lancar

Yang dimaksud dengan status dalam perhatian khusus adalah :

- Terdapat tunggakan kewajiban (angsuran pokok dan bunga maupun bunga saja) 91 hari sampai dengan 120 hari.

d) Diragukan

Yang dimaksud dengan status dalam perhatian khusus adalah :

- Terdapat tunggakan kewajiban (angsuran pokok dan bunga maupun bunga saja) 121 hari sampai dengan 180 hari.

e) Macet

Yang dimaksud dengan status dalam perhatian khusus adalah :

- Terdapat tunggakan kewajiban (angsuran pokok dan bunga maupun bunga saja) 121 hari sampai dengan 180 hari.

2. Jumlah kepemilikan kartu kredit.

Jumlah kepemilikan kartu kredit adalah banyaknya fasilitas kartu kredit yang dimiliki oleh debitur, data diambil pada rangkuman data debitur pada saat pengajuan fasilitas di CCBI dimana yang diambil adalah data yang ditarik melalui sistem informasi debitur dari pusat data Bank Indonesia yang biasa dikenal dengan istilah "BI Checking". Pada data bi checking informasi yang tertera adalah fasilitas yang diterima, jumlah plafond, suku bunga, bank pemberi fasilitas, data jaminan dan data profil debitur. 
3. Jenis kelamin.

Data jenis kelamin pria dan wanita diambil untuk dianalisa karena debitur di Bank saat ini mayoritas perorangan pria maupun wanita, sedangkan untuk pinjaman komersial mayoritas berbentuk badan hukum.

4. Pengalaman Debitur (Kerja atau usaha).

Data pengalaman yang dimaksud adalah lamanya debitur dalam menjalankan usaha atau bekerja yang dianalisa pada saat pengajuan fasilitas pinjaman di CCBI.

5. Status pernikahan.

Data status pernikahan Debitur diambil berdasarkan dokumen yang dilampirkan pada saat pengumpulan dokumen syarat pengajuan kredit khususnya dokumen identitas debitur seperti kartu tanda penduduk (KTP), kartu keluarga (KK) dan akta nikah.

Selanjutnya data tersebut diolah menggunakan analisa regresi untuk mengetahui pengaruh setiap data debitur terhadap tingkat kolektibilitas.

Hipotesa dari data permulaan dari calon debitur adalah

H1 : Semakin banyak Debitur memiliki kartu kredit maka semakin tinggi tingkat kolektibilitasnya.

$\mathrm{H} 2$ : Pria memiliki tingkat kolektibilitas lebih tinggi daripada wanita.

H3 : Semakin lama bekerja ataupun berbisnis (pengalaman) maka tingkat kolektibiltasnya semakin rendah.

H4 : Debitur yang menikah tingkat kolektibiltasnya semakin tinggi.

Untuk menjawab seluruh hipotesa tersebut dilakukan analisa regresi atas 68 debitur PT. Bank China Construction Bank Indonesia Tbk yang mendapatkan kredit dan memiliki tingkat kolektibilitas yang berbeda-beda. Hasil analisa regresi diharapkan dapat memberikan gambaran tentang faktor dominan yang akan mempengaruhi kolektibilitas dan dapat dipakai pihak bank dalam memutuskan pemberian kredit. 


\section{ANALISIS DATA}

Dari data yang didapatkan dilakukan analisa regresi terhadap data permulaan debitur untuk mengetahui keterkaitan antara faktor yang dinilai dengan tingkat kolektibilitas setiap debitur.

$$
\begin{aligned}
& \mathrm{Y}=f(\mathrm{X} 1, \mathrm{X} 2, \mathrm{X} 3, \mathrm{X} 4) \\
& \mathrm{Y}=\text { Tingkat kolektibilitas } \\
& \mathrm{X} 1=\text { Kartu kredit yang dimiliki } \\
& \mathrm{X} 2=\text { Jenis kelamin } \\
& \mathrm{X} 3=\text { Pengalaman (kerja / usaha) } \\
& \mathrm{X} 4=\text { Status pernikahan }
\end{aligned}
$$

Hasil analisa regresi sebagai berikut :

$$
\text { Tabel } 1
$$

Summary Output

\begin{tabular}{|l|r|}
\hline \multicolumn{2}{|c|}{ Regression Statistics } \\
\hline Multiple R & 0,443178652 \\
\hline R Square & 0,196407318 \\
\hline Adjusted R Square & 0,14538556 \\
\hline Standard Error & 0,97952624 \\
\hline Observations & 68 \\
\hline
\end{tabular}

Tabel ini menunjukan besarnya korelasi/varian antara variabel tidak bebas (dependent variable, dalam hal ini tingkat kolektibilitas) dengan variabel bebas (independent variable, dalam hal ini jumah kartu kredit,jenis kelamin, pengalaman dan status perkawinan.

Dari semua parameter yang ada pada tabel tersebut, parameter $\mathrm{R}$ Square yang biasanya digunakan untuk menentukan bagus tidaknya korelasi/variasi model hasil regresi (walaupun ada juga yang menggunakan Multiple R atau Adjusted R Square). Sebagai panduan umum, R 
Square 0.19 menunjukan varian model memiliki pengaruh terhadap variabel tidak bebas (Y). $\mathrm{R}$ square sebesar 0.19 seperti yang dihasilkan pada tabel juga masih cukup baik, ia mengandung pengertian bahwa seluruh variabel bebas (jumlah kartu kredit, jenis kelamin, pengalaman kerja / usaha dan status pernikahan) memiliki pengaruh terhadap tingkat kolektibilitas namun tidak cukup kuat karena hanya mempengaruhi sebesar $19.6 \%$ sementara sisanya dipengaruhi oleh variabel lainnya.

Tabel 2

Hasil Analisa Anova

\begin{tabular}{|l|r|r|r|r|r|}
\hline & \multicolumn{1}{|c|}{$d f$} & \multicolumn{1}{c|}{ SS } & \multicolumn{1}{c|}{ MS } & \multicolumn{1}{c|}{$F$} & Significance $F$ \\
\hline Regression & 4 & 14,77387396 & 3,69346849 & 3,849481608 & 0,007331124 \\
\hline Residual & 63 & 60,44671428 & 0,959471655 & & \\
\hline Total & 67 & 75,22058824 & & & \\
\hline
\end{tabular}

Dalam regresi, ANOVA digunakan untuk mengetes tingkat kebenaran/signifikan model hasil regresi secara keseluruhan (overall model). Parameter yang menentukan tingkat signifikan model regresi adalah yang berada pada kolom paling kanan, yaitu Significance F. Parameter ini disebut juga p-value. Tingkat signifikan model naik jika Significance F turun. Significance F mendekati nol berarti variabel bebas (X) sangat (signifikan) berpengaruh pada variabel terikat (Y).

Untuk contoh ini nilai Significance F adalah 0,07331124<0.05 (alfa), maka dapat disimpulkan bahwa jumlah kartu kredit, jenis kelamin, pengalaman kerja / usaha dan status pernikahan secara bersama-sama berpengaruh terhadap tingakat kolektibilitas debitur.

Tabel 3

Coefficients

\begin{tabular}{|c|c|c|c|c|c|c|c|c|}
\hline & Coefficients & Standard Error & t Stat & P-value & Lower 95\% & Upper 95\% & Lower $95,0 \%$ & Upper $95,0 \%$ \\
\hline Intercept & 1,2684711 & 0,26396958 & 4,805368305 & 9,94489E-06 & 0,740969939 & 1,795972167 & 0,740969939 & 1,795972167 \\
\hline CC yang dimiliki & $-0,020714$ & 0,034899196 & $-0,593551077$ & 0,554937553 & $-0,090454933$ & 0,049026022 & $-0,090454933$ & 0,049026022 \\
\hline Jenis Kelamin & $-0,280507$ & 0,249 & $-1,123863861$ & 0,26 & $-0,779275501$ & 1897 & $-0,779275501$ & 1897 \\
\hline Pengalaman (kerja/usaha) & 0,0788903 & 0,021195175 & 3,722086188 & 0,000423561 & 0,03653509 & 0,12124544 & 0,03653509 & 0,12124544 \\
\hline Status Perkawinan & $-0,300912$ & 0,420940732 & $-0,714856816$ & 0,477338244 & $-1,142095283$ & 0,54027058 & $-1,142095283$ & 0,54027058 \\
\hline
\end{tabular}

Dari tabel diatas dapat dilihat pada kolom P-value bahwa hasil regresi untuk masing-masing variabel memiliki hasil yang berbeda-beda. Dan hanya variabel pengalaman kerja / usaha yang 
memiliki pengaruh yang signifikan terhadap tingkat kolektibilitas debitur ( $\mathrm{P}$ value $0.000423561<$ alfa 0.005) hal ini tidak mendukung penelitian Koesrindartoto dan Pratiwi th. 2010. Sementara untuk variabel jumah kartu kredit, jenis kelamin dan status pernikahan secara parsial tidak memiliki pengaruh yang signifikan terhadap tingkat kolektibilitas debitur. Berdasarkan ketentuan dari Bank Indonesia terkait pengelompokan status pinjaman debitur di Bank dalam rentang tingkatan 1 (satu) sampai dengan 5 (lima), tingkat kolektibilitas dikatakan sebagai kolektibilitas tingkat 1 (satu) atau rendah jika statusnya lancar. Sebaliknya tingkat kolektibilitas dikatakan sebagai kolektibilitas 5 (lima) atau tinggi jika statusnya macet.

\section{KESIMPULAN}

Berdasarkan hasil analisa regresi dapat disimpulkan bahwa semua data permulaan (variable bebas atau $\mathrm{X}$ ) yang diterima oleh CCBI dari calon debitur hanya dapat menjelaskan sebesar $19.6 \%$ saja pengaruh terhadap tingkat kolektibilitas debitur. Hal ini tergambarkan dari nilai R-square sebesar $19.6 \%$ yang memiliki arti bahwa kelima variabel tersebut mempengaruhi $19.6 \%$ tingkat kolektibilitas debitur dan masih ada sekitar $81.4 \%$ dipengaruhi oleh variabel lainnya.

Dari seluruh variabel yang diuji hanya faktor pengalaman bekerja / berbisnis yang berpengaruh pada tingkat kolektibilitas namun variable lainnya tidak berpengaruh terhadap tingkat kolektibilitas debitur oleh karena itu tidak bisa diketahui profil risiko seorang debitur hanya dengan melihat dari keempat variabel tersebut saja, dibutuhkan variabel lainnya untuk mengetahui apa yang mempengaruhi tingkat kolektibilitas pinjaman debitur/calon debitur.

\section{REKOMENDASI}

Penelitian selanjutnya dapat dilakukan dengan meneliti faktor demografi lain selain yang sudah dilakukan dalam penelitian ini atau faktor-faktor lainnya selain demografi, agar pihak bank dapat semakin tajam dalam menganalisa tingkat kolektibilitas calon debitur, selain itu dapat diperluas dengan menggunakan data dari bank lain agar dapat diketahui perbandingannya. 
Selain itu. metode kualitatif berupa wawancara dan observasi mendalam terhadap subjek debitur yang memiliki pengalaman bekerja / berbisnis yang beragam juga dapat dilakukan untuk mempertajam hasil analisa data dalam penelitian ini serta membuka kemungkinan untuk hasil temuan lain. 


\section{DAFTAR PUSTAKA}

http://fnistatistics.com/divisi_detail.php?id=114 (diakses tanggal 7 Agustus 2017) http://sbm.binus.ac.id/2015/11/20/alpha-dan-p-value-dalam-statistik/ (diakses tanggal 7 Agustus 2017)

https://asro.wordpress.com/2009/07/28/penggunaan-fungsi-regresi-excell-untukpemodelan-inferential/ (diakses tanggal 7 Agustus 2017)

Kassim, Salina \& Majid, Shabri (2008) The role of bank loans and deposits in the monetary transmission mechanism in Malaysia

Warjiyo, Perry (2006), Stabilitas Sistem Perbankan dan Kebijakan Moneter: Keterkaitan dan perkembangannya di Indonesia.

Mansfield, Phylis M; Pinto, Mary Beth; Robb, Cliff A (2012) Consumers and Credit Cards : A Review of the Empirical Literature

Ramayah, T; Noor, Nasser; Nasurdin, Aizzat Mohd; Choo, Lim Hee (2002) Cardholders Attitude and Bank Credit Card Usage In Malaysia : An Exploratory Study

Noordin, Nazni; Zakaria, Zaherawati; Sawal, Mohd Zool Hilmie; Ngah, Kamarudin; Hussin, Zaliha (2012) Bangkruptcy among young Executives in Malaysia Nijam, HM (2013) Owner's Demographics and Ownership Information in Exlaining Credit Repayment Behaviour of Micro Small and Medium Sized Enterprises

Koesrindartoto, Deddy P ; Pratiwi, Mega (2010) Collectibility Analysis for Small and Medium Enterprise - Bank Bukopin Case Waweru,Charlene (2010) Factors Influencing Repayment of Bank Loans: A Case of NIC Bank Limited, Nairobi Province Kenya 
VIII. LAMPIRAN

Data

\begin{tabular}{|c|c|c|c|c|c|}
\hline No & Kolektibilitas & $\begin{array}{l}\text { CC yang } \\
\text { dimiliki }\end{array}$ & $\begin{array}{c}\text { Jenis } \\
\text { Kelamin }\end{array}$ & $\begin{array}{c}\text { Lama } \\
\text { bekerja/usaha }\end{array}$ & \begin{tabular}{|c} 
Status \\
Perkawinan
\end{tabular} \\
\hline 1 & 1 & 4 & 0 & 7 & 0 \\
\hline 2 & 2 & 11 & 1 & 8 & 0 \\
\hline 3 & 1 & 1 & 1 & 14 & 0 \\
\hline 4 & 1 & 2 & 1 & 5 & 0 \\
\hline 5 & 1 & 2 & 1 & 2 & 0 \\
\hline 6 & 1 & 1 & 1 & 12 & 0 \\
\hline 7 & 1 & 4 & 0 & 5 & 0 \\
\hline 8 & 2 & 1 & 0 & 3 & 0 \\
\hline 9 & 1 & 3 & 1 & 15 & 0 \\
\hline 10 & 1 & 6 & 1 & 6 & 0 \\
\hline 11 & 1 & 15 & 0 & 5 & 0 \\
\hline 12 & 2 & 11 & 0 & 10 & 0 \\
\hline 13 & 2 & 13 & 1 & 13 & 0 \\
\hline 14 & 1 & 2 & 0 & 5 & 0 \\
\hline 15 & 2 & 2 & 1 & 16 & 0 \\
\hline 16 & 1 & 4 & 1 & 1 & 0 \\
\hline 17 & 1 & 4 & 1 & 5 & 0 \\
\hline 18 & 1 & 0 & 1 & 2 & 0 \\
\hline 19 & 1 & 4 & 0 & 2 & 0 \\
\hline 20 & 1 & 5 & 1 & 11 & 0 \\
\hline 21 & 1 & 5 & 1 & 11 & 0 \\
\hline 22 & 1 & 3 & 1 & 3 & 0 \\
\hline 23 & 1 & 7 & 1 & 6 & 0 \\
\hline 24 & 1 & 4 & 0 & 6 & 0 \\
\hline 25 & 2 & 2 & 0 & 1 & 0 \\
\hline 26 & 2 & 3 & 1 & 11 & 0 \\
\hline 27 & 1 & 3 & 1 & 10 & 0 \\
\hline 28 & 1 & 2 & 1 & 2 & 0 \\
\hline 29 & 1 & 4 & 1 & 15 & 0 \\
\hline 30 & 1 & 4 & 1 & 9 & 0 \\
\hline 31 & 1 & 5 & 1 & 5 & 0 \\
\hline 32 & 1 & 1 & 1 & 6 & 1 \\
\hline 33 & 1 & 1 & 1 & 2 & 0 \\
\hline 34 & 1 & 1 & 0 & 2 & 0 \\
\hline 35 & 5 & 3 & 1 & 5 & 0 \\
\hline
\end{tabular}




\begin{tabular}{|c|c|c|c|c|c|}
\hline 36 & 1 & 3 & 0 & 19 & 0 \\
\hline 37 & 1 & 2 & 0 & 10 & 0 \\
\hline 38 & 1 & 1 & 1 & 6 & 0 \\
\hline 39 & 2 & 3 & 0 & 6 & 0 \\
\hline 40 & 1 & 1 & 1 & 2 & 1 \\
\hline 41 & 1 & 3 & 1 & 2 & 1 \\
\hline 42 & 1 & 0 & 0 & 5 & 1 \\
\hline 43 & 1 & 2 & 0 & 2 & 0 \\
\hline 44 & 1 & 1 & 1 & 7 & 0 \\
\hline 45 & 1 & 8 & 1 & 20 & 0 \\
\hline 46 & 2 & 1 & 0 & 2 & 0 \\
\hline 47 & 1 & 2 & 1 & 9 & 0 \\
\hline 48 & 1 & 2 & 0 & 0 & 0 \\
\hline 49 & 2 & 3 & 1 & 2 & 0 \\
\hline 50 & 1 & 3 & 1 & 10 & 0 \\
\hline 51 & 2 & 2 & 0 & 15 & 0 \\
\hline 52 & 2 & 0 & 1 & 18 & 0 \\
\hline 53 & 3 & 2 & 0 & 14 & 1 \\
\hline 54 & 5 & 0 & 0 & 16 & 0 \\
\hline 55 & 2 & 3 & 1 & 8 & 0 \\
\hline 56 & 3 & 0 & 1 & 7 & 0 \\
\hline 57 & 4 & 6 & 1 & 17 & 0 \\
\hline 58 & 2 & 8 & 1 & 14 & 0 \\
\hline 59 & 2 & 2 & 0 & 4 & 0 \\
\hline 60 & 2 & 8 & 1 & 20 & 0 \\
\hline 61 & 1 & 14 & 0 & 15 & 1 \\
\hline 62 & 3 & 14 & 1 & 21 & 0 \\
\hline 63 & 5 & 10 & 1 & 15 & 0 \\
\hline 64 & 2 & 5 & 1 & 15 & 0 \\
\hline 65 & 5 & 0 & 0 & 25 & 0 \\
\hline 66 & 2 & 0 & 0 & 4 & 0 \\
\hline 67 & 2 & 2 & 0 & 6 & 0 \\
\hline 68 & 2 & 2 & 1 & 5 & 0 \\
\hline
\end{tabular}


Vol.01, No. 2, 2018

\begin{tabular}{|c|c|c|c|c|c|c|c|c|}
\hline No & \multicolumn{2}{|c|}{ Kolektibilitas } & CC yang & \multicolumn{2}{|c|}{ Jenis Kelamin } & \multirow[t]{2}{*}{ Pengalaman } & & \multirow{2}{*}{$\begin{array}{c}\begin{array}{c}\text { Status } \\
\text { Perkawinan }\end{array} \\
\text { Menikah }\end{array}$} \\
\hline 1 & 1 & Lancar & & 0 & Wanita & & 0 & \\
\hline 2 & 2 & $\begin{array}{l}\text { Dalam } \\
\text { Perhatian } \\
\text { Khusus }\end{array}$ & & 1 & Pria & & 1 & Tidak Menikah \\
\hline 3 & 3 & $\begin{array}{l}\text { Kurang } \\
\text { Lancar }\end{array}$ & & & & & & \\
\hline 4 & 4 & Diragukan & & & & & & \\
\hline 5 & 5 & Macet & & & & & & \\
\hline
\end{tabular}

\section{SUMMARY OUTPUT}

\begin{tabular}{|l|r|}
\hline \multicolumn{2}{|c|}{ Regression Statistics } \\
\hline Multiple R & 0,4431787 \\
\hline R Square & 0,1964073 \\
\hline Adjusted R Square & 0,1453856 \\
\hline Standard Error & 0,9795262 \\
\hline Observations & 68 \\
\hline
\end{tabular}

ANOVA

\begin{tabular}{|l|r|r|r|r|r|}
\hline & \multicolumn{1}{|c|}{$d f$} & \multicolumn{1}{|c|}{ SS } & \multicolumn{1}{c|}{ MS } & \multicolumn{1}{c|}{$F$} & Significance $F$ \\
\hline Regression & 4 & 14,77387396 & 3,69346849 & 3,849481608 & 0,007331124 \\
\hline Residual & 63 & 60,44671428 & 0,959471655 & & \\
\hline Total & 67 & 75,22058824 & & & \\
\hline
\end{tabular}

\begin{tabular}{|l|r|r|r|r|r|r|r|r|}
\hline & Coefficients & Standard Error & \multicolumn{1}{c|}{ Stat } & \multicolumn{1}{c|}{-value } & \multicolumn{1}{c}{ Lower 95\% } & Upper 95\% & Lower 95,0\% & Upper 95,0\% \\
\hline Intercept & 1,2684711 & 0,26396958 & 4,805368305 & $9,94489 \mathrm{E}-06$ & 0,740969939 & 1,795972167 & 0,740969939 & 1,795972167 \\
\hline CC yang dimiliki & $-0,020714$ & 0,034899196 & $-0,593551077$ & 0,554937553 & $-0,090454933$ & 0,049026022 & $-0,090454933$ & 0,049026022 \\
\hline Jenis Kelamin & $-0,280507$ & 0,249591443 & $-1,123863861$ & 0,265335007 & $-0,779275501$ & 0,218261897 & $-0,779275501$ & 0,218261897 \\
\hline Pengalaman (kerja/usaha) & $\mathbf{0 , 0 7 8 8 9 0 3}$ & $\mathbf{0 , 0 2 1 1 9 5 1 7 5}$ & $\mathbf{3 , 7 2 2 0 8 6 1 8 8}$ & $\mathbf{0 , 0 0 0 4 2 3 5 6 1}$ & $\mathbf{0 , 0 3 6 5 3 5 0 9}$ & $\mathbf{0 , 1 2 1 2 4 5 4 4}$ & $\mathbf{0 , 0 3 6 5 3 5 0 9}$ & $\mathbf{0 , 1 2 1 2 4 5 4 4}$ \\
\hline Status Perkawinan & $-0,300912$ & $\mathbf{0 , 4 2 0 9 4 0 7 3 2}$ & $-0,714856816$ & 0,477338244 & $-1,142095283$ & 0,54027058 & $-1,142095283$ & 0,54027058 \\
\hline
\end{tabular}


RESIDUAL OUTPUT

\begin{tabular}{rrrr}
\hline Observation & \multicolumn{1}{c}{$\begin{array}{c}\text { Predicted } \\
\text { Kolektibilitas }\end{array}$} & \multicolumn{1}{l}{ Residuals } \\
\hline 1 & 1,737845103 & $-0,737845103$ \\
2 & 1,391227382 & 0,608772618 \\
3 & 2,071713537 & $-1,071713537$ \\
4 & 1,340986676 & $-0,340986676$ \\
5 & 1,104315875 & $-0,104315875$ \\
6 & 1,913933002 & $-0,913933002$ \\
7 & 1,580064569 & $-0,580064569$ \\
8 & 1,4844274 & 0,5155726 \\
9 & 2,109174894 & $-1,109174894$ \\
10 & 1,337019123 & $-0,337019123$ \\
11 & 1,352205562 & $-0,352205562$ \\
12 & 1,829514719 & 0,170485281 \\
13 & 1,744249807 & 0,255750193 \\
14 & 1,621493479 & $-0,621493479$ \\
15 & 2,208779616 & $-0,208779616$ \\
16 & 0,983996697 & 0,016003303 \\
17 & 1,299557766 & $-0,299557766$ \\
18 & 1,145744785 & $-0,145744785$ \\
19 & 1,343393767 & $-0,343393767$ \\
20 & 1,752184914 & $-0,752184914$ \\
21 & 1,752184914 & $-0,752184914$ \\
22 & 1,162491687 & $-0,162491687$ \\
23 & 1,316304668 & $-0,316304668$ \\
24 & 1,658954836 & $-0,658954836$ \\
25 & 1,30593241 & 0,69406759 \\
& & \\
& & & \\
& & \\
& & \\
12 &
\end{tabular}

PROBABILITY OUTPUT

\begin{tabular}{|c|c|}
\hline Percentile & Kolektibilitas \\
\hline 0,735294118 & 1 \\
\hline 2,205882353 & 1 \\
\hline 3,676470588 & 1 \\
\hline 5,147058824 & 1 \\
\hline 6,617647059 & 1 \\
\hline 8,088235294 & 1 \\
\hline 9,558823529 & 1 \\
\hline 11,02941176 & 1 \\
\hline 12,5 & 1 \\
\hline 13,97058824 & 1 \\
\hline 15,44117647 & 1 \\
\hline 16,91176471 & 1 \\
\hline 18,38235294 & 1 \\
\hline 19,85294118 & 1 \\
\hline 21,32352941 & 1 \\
\hline 22,79411765 & 1 \\
\hline 24,26470588 & 1 \\
\hline 25,73529412 & 1 \\
\hline 27,20588235 & 1 \\
\hline 28,67647059 & 1 \\
\hline 30,14705882 & 1 \\
\hline 31,61764706 & 1 \\
\hline 33,08823529 & 1 \\
\hline 34,55882353 & 1 \\
\hline 36,02941176 & 1 \\
\hline
\end{tabular}


Vol.01, No. 2, 2018

\begin{tabular}{|c|c|c|c|}
\hline 26 & 1,793613825 & 0,206386175 & 37,5 \\
\hline 27 & 1,714723557 & $-0,714723557$ & 38,97058824 \\
\hline 28 & 1,104315875 & $-0,104315875$ & 40,44117647 \\
\hline 29 & 2,088460439 & $-1,088460439$ & 41,91176471 \\
\hline 30 & 1,615118835 & $-0,615118835$ & 43,38235294 \\
\hline 31 & 1,278843311 & $-0,278843311$ & 44,85294118 \\
\hline 32 & 1,139679047 & $-0,139679047$ & 46,32352941 \\
\hline 33 & 1,12503033 & $-0,12503033$ & 47,79411765 \\
\hline 34 & 1,405537132 & $-0,405537132$ & 49,26470588 \\
\hline 35 & 1,320272221 & 3,679727779 & 50,73529412 \\
\hline 36 & 2,705242765 & $-1,705242765$ & 52,20588235 \\
\hline 37 & 2,015944815 & $-1,015944815$ & 53,67647059 \\
\hline 38 & 1,440591399 & $-0,440591399$ & 55,14705882 \\
\hline 39 & 1,679669291 & 0,320330709 & 56,61764706 \\
\hline 40 & 0,824117978 & 0,175882022 & 58,08823529 \\
\hline 41 & 0,782689068 & 0,217310932 & 59,55882353 \\
\hline 42 & 1,362010037 & $-0,362010037$ & 61,02941176 \\
\hline 43 & 1,384822677 & $-0,384822677$ & 62,5 \\
\hline 44 & 1,519481666 & $-0,519481666$ & 63,97058824 \\
\hline 45 & 2,400053954 & $-1,400053954$ & 65,44117647 \\
\hline 46 & 1,405537132 & 0,594462868 & 66,91176471 \\
\hline 47 & 1,656547745 & $-0,656547745$ & 68,38235294 \\
\hline 48 & 1,227042143 & $-0,227042143$ & 69,85294118 \\
\hline 49 & 1,08360142 & 0,91639858 & 71,32352941 \\
\hline 50 & 1,714723557 & $-0,714723557$ & 72,79411765 \\
\hline 51 & 2,410396151 & $-0,410396151$ & 74,26470588 \\
\hline 52 & 2,407989061 & $-0,407989061$ & 75,73529412 \\
\hline 53 & 2,030593532 & 0,969406468 & 77,20588235 \\
\hline 54 & 2,530715329 & 2,469284671 & 78,67647059 \\
\hline 55 & 1,556943023 & 0,443056977 & 80,14705882 \\
\hline 56 & 1,540196121 & 1,459803879 & 81,61764706 \\
\hline 57 & 2,204812063 & 1,795187937 & 83,08823529 \\
\hline 58 & 1,926712351 & 0,073287649 & 84,55882353 \\
\hline 59 & 1,542603212 & 0,457396788 & 86,02941176 \\
\hline 60 & 2,400053954 & $-0,400053954$ & 87,5 \\
\hline 61 & 1,860910337 & $-0,860910337$ & 88,97058824 \\
\hline 62 & 2,35465749 & 0,64534251 & 90,44117647 \\
\hline 63 & 1,964173707 & 3,035826293 & 91,91176471 \\
\hline 64 & 2,067745983 & $-0,067745983$ & 93,38235294 \\
\hline 65 & 3,240727734 & 1,759272266 & 94,85294118 \\
\hline 66 & 1,584032122 & 0,415967878 & 96,32352941 \\
\hline 67 & 1,700383746 & 0,299616254 & 97,79411765 \\
\hline 68 & 1,340986676 & 0,659013324 & 99,26470588 \\
\hline
\end{tabular}

